\title{
Overcoming Barriers in the Management of Hypertension: The Experience of the Cardiovascular Health Program in Chilean Primary Health Care Centers
}

\author{
Daniela Sandoval, ${ }^{1}$ Miguel Bravo, ${ }^{2}$ Elard Koch, ${ }^{1,2}$ Sebastián Gatica, ${ }^{2}$ Ivonne Ahlers, ${ }^{1}$ \\ Oscar Henríquez, ${ }^{1}$ and Tomás Romero ${ }^{3,4}$ \\ ${ }^{1}$ Department of Family Medicine \& Primary Care, Faculty of Medicine, University of Chile, 8380453 Santiago, Chile \\ ${ }^{2}$ Institute of Molecular Epidemiology (MELISA), Faculty of Medicine, Universidad Católica de la Santísima Concepción, \\ 4070129 Concepción, Chile \\ ${ }^{3}$ School of Medicine, University of California, San Diego, CA 92093, USA \\ ${ }^{4}$ Fundacion Araucaria Foundation, Coronado, CA 92118, USA
}

Correspondence should be addressed to Daniela Sandoval, dsandovalh@gmail.com

Received 7 January 2012; Accepted 7 February 2012

Academic Editor: Kazuko Masuo

Copyright ( 2012 Daniela Sandoval et al. This is an open access article distributed under the Creative Commons Attribution License, which permits unrestricted use, distribution, and reproduction in any medium, provided the original work is properly cited.

Objective. To assess the blood pressure control and cardiovascular risk factors (CVRFs) in a population of hypertensive patients with access to care under a government-financed program, the Cardiovascular Health Program (CHP). Design. A cross-sectional and multicenter study. Setting. 52 primary care centers, metropolitan area of Santiago, Chile. Participants. 1,194 patients were selected by a systematic random sampling from a universe of 316,654 hypertensive patients. Key Measurements. Demographic information, blood pressure (BP) measurements, and CVRF were extracted from medical records of patients followed for a 12month period. Results. $59.7 \%$ of patients reached target BP $<140 / 90 \mathrm{mmHg}$. More women were captured in the sampling (2.1: 1 ), achieving better BP control than men. Diabetic patients $(26.4 \%)$ had worse BP control than nondiabetics. Antihypertensive medications were used in $91.5 \%$, with multidrug therapy more frequent in patients with higher BP and more difficult control. Conclusions. The success in improving the BP control to values $<140 / 90 \mathrm{mmHg}$ from $45.3 \%$ to $59.7 \%$ underscores the contribution of this program in the Chilean primary care cardiovascular preventive strategies. However, fewer hypertensive men than women were captured by this program, and it is of concern the underperforming of BP control observed in diabetics.

\section{Introduction}

Hypertension control has been instrumental to achieve a significant reduction in cardiovascular events. However, despite the advancements in antihypertensive drug therapy, success in controlling BP to the Joint National Committee VII guidelines $(\mathrm{BP}<140 / 90 \mathrm{mmHg}$ ) has been quite disappointing. Most of the published information has reported satisfactory BP control in only $30 \%$ to $45 \%$ of the hypertensive population [1-5].

Numerous factors have been mentioned as responsible for this limited results including socioeconomic status, barriers in the access to health care, lack of a populationoriented program focused on preventive cardiovascular measures, poor adherence, among others [1, 6-8]. The Chilean Ministry of Health started a Cardiovascular Health Program (CHP) (Programa de Salud Cardiovascular, PSCV) in 2002 with the objective of reducing the cardiovascular morbidity and mortality by a global management strategy of cardiovascular risk factors (CVRF) in patients followed at the primary care level $[9,10]$. Approximately $76.9 \%$ of the Chilean population is enrolled in a primary care clinic through the public health system. This is financed by the Ministry of Health through subsidies to the primary care 
centers and clinics, some of them belonging to the private sector [9]. Patients have access to the CHP once a diagnosis of hypertension, diabetes, and/or dyslipidemia is established after the initial primary care evaluation. By law every patient enrolled in the public health system is eligible for a preventive annual medical examination. Patients referred to the CHP receive free followup and drug therapy at least every three months through multidisciplinary teams composed by primary care physicians, nurses, dietitians, and social workers. Patients are referred to a secondary health care system when secondary hypertension is suspected or when they develop complications such as ischemic heart disease, congestive heart failure, cerebrovascular accident, and renal failure. Currently, 1,485,862 patients are enrolled nationwide in the CHP and near 400,000 patients in the metropolitan area of Santiago.

The objectives of this study were twofold. First, to evaluate the proportion of CVRF in hypertensive patients, with or without diabetes, followed under the CHP and, second, to assess the efficacy of this program in the blood pressure control on this population.

\section{Methods}

2.1. Population Sample and Procedures. A multicenter crosssectional systematically randomized sample from a universe of 316,654 hypertensive patients followed throughout the CHP in 133 primary care centers was obtained from 52 municipalities of the metropolitan region of Santiago, Chile. Patients who had BP readings $\geq 140 / 90 \mathrm{mmHg}$ throughout their routine medical followups were referred to the CHP. Primary care centers with $>1,000$ hypertensive patients (97 from 133 centers) were randomly selected, one per each of the 52 municipalities. A randomly selected sample of 1,194 hypertensive patients representing proportionally the total number of patients followed in each one of the primary care centers selected was included in the study. The sampling size $(n=1,194)$ was obtained with $95 \%$ of confidence, estimated error of 5\%, expected prevalence of BP $<140 / 90 \mathrm{mmHg}$ of $50 \%$, and design effect of 3.0. Patients were given follow-up appointments according to the clinical assessment and a minimum of three visits per year after the initial evaluation. Patients under 20 years of age, or suffering significant disabilities (bedridden, mentally incompetent, wheel chair users), or with missing appointments (less than three followup visits per year) were excluded $(n=23)$. After replacing the exclusions according to a random procedure using the EPI-Info software, each patient was randomly selected in every one of the primary care centers included.

The data collection was completed in November 2006. The medical records of 12 consecutive months of followup were reviewed. Systolic and diastolic blood pressure (SBP and DBP, resp.) measured by trained personnel throughout 3 successive controls at the corresponding CHP primary care center according to international guidelines [5] and using mercury sphygmomanometers was included for data analysis. Occasional BP measurements performed outside the CHP were not considered. Age, gender, weight, height, education level (years of schooling), and smoking habit (daily smokers) were recorded. Presence of diabetes was established by clinical diagnosis and/or therapies prescribed. All the antihypertensive medications were recorded. Cholesterol levels (total and HDL) were obtained by standard techniques and included for data analysis and only the last ones recorded throughout the follow-up period.

All patients received lifestyle changes counseling (diet, smoking cessation, physical activities) and antihypertensive therapy freely prescribed and adjusted by the physician during the follow-up visits in every primary care center.

2.2. Statistical Analysis. The demographic distribution by gender and age of the 316,654 patients was used to calculate the base weight for each sampling unit. Absolute expansion sample weights were calculated using the respective geographical distribution of each one of the primary care centers included in the study allowing to minimize selection bias. Internal and external validity was established by the $Z$-binomial test comparing the sample $(1,194)$ and the universe $(316,654)$. A multivariate logistical analysis was performed to calculate the odds ratio (OR) $95 \%$ confidence intervals for the proportion of CVFR (high blood pressure, total cholesterol, HDL cholesterol, body mass index (BMI), smoking, education level) in hypertensive diabetic and nondiabetic patients. In addition, the association between the control of BP and different factors was assessed in age- and sex-adjusted logistic regression models.

\section{Results}

The age distribution showed no statistically significant differences between the universe and the sample. Mean age was $63.7 \pm 13.6$ years, with no differences between men and women $(64.5 \pm 13.1$ versus $63.7 \pm 13.6$ years, $P=0.13)$ (Table 1). A small proportion of patients with stable cardiovascular comorbidities under routine specialized care were observed in the sample: ischemic heart disease, $1.5 \%$; congestive heart failure, $3.8 \%$; cerebrovascular accident, $3.2 \%$; renal failure, $1.9 \%$; arrhythmias, $1.6 \%$.

More hypertensive women than men were captured by the CHP (ratio 2.1:1). Table 2 includes the CVRF values (\%) in this population. Women had a higher proportion of obesity than men $(47.9 \%$ versus $33.1 \%, P<0.01)$ and HDL $<50 \mathrm{mg} / \mathrm{dL}$ in $51.8 \%$; in contrast, men had $\mathrm{HDL}<40 \mathrm{mg} / \mathrm{dL}$ in $33.2 \%(P<0.01)$. Men exhibited higher proportion of smoking, overweight $\left(\mathrm{BMI}>25-30 \mathrm{~kg} / \mathrm{m}^{2}\right)$, and diabetes than women $(P<0.01)$. Table 3 compares the CVRF expressed as percentage found in this study with the results reported by the 2010 Chilean National Health Survey [11] in hypertensive and normal individuals.

The mean SBP was $135 \pm 15 \mathrm{mmHg}$, and it was higher in men than in women $(138 \pm 16$ versus $135 \pm 15 \mathrm{mmHg}$, resp., $P<0.01)$. The mean DBP was $81 \pm 10 \mathrm{mmHg}$, with no statistically significant differences by gender. It is of note that $59.7 \%$ of the patients achieved a $\mathrm{BP}<140 / 90 \mathrm{mmHg}$, although women had a larger proportion of controlled BP than men $(63.7 \%$ versus $52.4 \%, P<0.01)$. 
TABle 1: Age and gender distribution. Comparison of the weighted sample $(n=1,194)$ and the total hypertensive population $(n=316,654)$ followed in the Cardiovascular Health Program (CHP), metropolitan area, Santiago, Chile.

\begin{tabular}{|c|c|c|c|c|c|c|c|c|c|c|}
\hline \multirow{3}{*}{$\begin{array}{l}\text { Age } \\
\text { (years) }\end{array}$} & \multicolumn{5}{|c|}{ Men } & \multicolumn{5}{|c|}{ Women } \\
\hline & \multicolumn{2}{|c|}{ Sample } & \multicolumn{2}{|c|}{ Hypertensive population } & \multirow{2}{*}{$P$-value } & \multicolumn{2}{|c|}{ Sample } & \multicolumn{2}{|c|}{ Hypertensive population } & \multirow{2}{*}{$P$-value } \\
\hline & $n$ & $\%$ & $N$ & $\%$ & & $n$ & $\%$ & $N$ & $\%$ & \\
\hline $20-34$ & 7 & 1.9 & 2,102 & 2.2 & 0.68 & 18 & 2.3 & 4,793 & 2.2 & 0.91 \\
\hline $35-44$ & 22 & 5.7 & 6,186 & 6.3 & 0.61 & 64 & 7.7 & 18,875 & 8.7 & 0.29 \\
\hline $45-54$ & 63 & 16.4 & 14,546 & 14.9 & 0.41 & 147 & 18.1 & 41,567 & 19.2 & 0.31 \\
\hline $55-64$ & 85 & 22.4 & 24,465 & 25.0 & 0.24 & 203 & 25.0 & 54,626 & 25.3 & 0.93 \\
\hline 65 or more & 204 & 53.6 & 50,262 & 51.4 & 0.38 & 381 & 46.9 & 96,232 & 44.5 & 0.20 \\
\hline Total & 381 & 100 & 97,561 & 100 & & 813 & 100 & 216,093 & 100 & \\
\hline
\end{tabular}

TABLe 2: Percentage of cardiovascular risk factors by gender (weighted sample).

\begin{tabular}{|c|c|c|c|}
\hline & $\begin{array}{c}\text { Men } \\
n=381\end{array}$ & $\begin{array}{l}\text { Women } \\
n=813\end{array}$ & $\begin{array}{c}\text { Total } \\
n=1,194\end{array}$ \\
\hline \multirow[t]{2}{*}{ Average age (years) } & $63.7 \pm 13.6$ & $64.5 \pm 13.1$ & $63.3 \pm 13.6$ \\
\hline & & Percentage \% (CI 95\%) & \\
\hline $\begin{array}{l}\text { Diabetes mellitus } \\
\quad \text { (clinical diagnosis) }\end{array}$ & $27.5(27.2-27.8)$ & $25.9(25.7-26.1)^{*}$ & $26.4(26.2-26.5)$ \\
\hline $\begin{array}{l}\text { Glycemia } \\
\quad \geq 100 \mathrm{mg} / \mathrm{dL}\end{array}$ & $48.9(48.5-49.1)$ & $42.2(41.9-42.4)^{*}$ & $44.3(44.1-44.5)$ \\
\hline $\begin{array}{l}\text { Overweight } \\
\qquad \text { BMI }>25-29 \mathrm{Kg} / \mathrm{m}^{2}\end{array}$ & $47.1(46.8-47.4)$ & $35.5(35.3-35.6)^{*}$ & $39.4(36.6-42.2)$ \\
\hline $\begin{array}{l}\text { Obesity } \\
\qquad \mathrm{BMI} \geq 30 \mathrm{Kg} / \mathrm{m}^{2}\end{array}$ & $33.1(32.8-33.4)$ & $47.9(47.7-48.1)^{*}$ & $42.8(42.2-43.4)$ \\
\hline $\begin{array}{l}\text { Total cholesterol } \\
200-239 \mathrm{mg} / \mathrm{dL}\end{array}$ & $36.6(36.3-36.9)$ & $34.8(34.6-35.0)^{*}$ & $35.4(35.2-35.5)$ \\
\hline $\begin{array}{l}\text { Total cholesterol } \\
\quad \geq 240 \mathrm{mg} / \mathrm{dL}\end{array}$ & $16.1(15.8-16.3)$ & $26.1(25.9-26.3)^{*}$ & $23.0(22.8-23.1)$ \\
\hline $\begin{array}{l}\text { Cholesterol HDL } \\
\quad<40 \mathrm{mg} / \mathrm{dL}\end{array}$ & $33.2(32.8-33.5)$ & - & - \\
\hline $\begin{array}{l}\text { Cholesterol HDL } \\
<50 \mathrm{mg} / \mathrm{dL}\end{array}$ & - & $51.8(51.6-52.0)^{*}$ & - \\
\hline Smoking & $21.2(20.9-21.5)$ & $16.5(16.3-16.7)^{*}$ & $18.0(17.9-18.1)$ \\
\hline $\begin{array}{l}\text { Low education } \\
\quad<8 \text { years }\end{array}$ & $56.1(55.8-56.5)$ & $60.1(59.8-60.4)^{*}$ & $58.8(58.6-59.1)$ \\
\hline
\end{tabular}

There were no statistically significant age differences between diabetic and nondiabetic hypertensive patients $(64.0 \pm$ 12.2 versus $62.9 \pm 14.0$ years; $P=0.18$ ). Hypertensive diabetic patients had worse BP control than nondiabetics, achieving a BP $<140 / 90 \mathrm{mmHg}$ in $53.2 \%$ versus $62.4 \%$, respectively $(P<0.01)$, difference that persists although attenuated when considering a level of control $<130 / 80 \mathrm{mmHg}(21.5 \%$ versus $24.9 \%, P<0.01)$ (Table 4 , Figure 1). Hypertensive diabetic patients also had a higher proportion of obesity (BMI $>30 \mathrm{~kg} / \mathrm{m}^{2}$ ) and low HDL $(<40 \mathrm{mg} / \mathrm{dL}$ ) than nondiabetics (Table 4 ). After adjusting by age and gender, diabetes and low education level were associated with $\mathrm{BP} \geq 140 / 90 \mathrm{mmHg}$ (OR 1.39 and 1.29, resp., Table 5) and, to a lesser extent, total cholesterol, low HDL cholesterol, and BMI $>30 \mathrm{~kg} / \mathrm{m}^{2}$. Coexisting incidental cardiovascular diseases were associated to $\mathrm{BP}<140 / 90 \mathrm{mmHg}$ (OR 0.77).

A large percentage of patients $(91.5 \%)$ received antihypertensive drug therapy (34.3\% monotherapy and $57.1 \%$ combination of drugs). Angiotensin-converting enzyme inhibitors (ACEIs), diuretics, calcium channel, and $\beta$-blockers were the more frequently used drugs (Figure 2). Exclusively nonpharmacological measures were used in $8.5 \%$ of patients, and $75 \%$ of them achieved a BP $<140 / 90 \mathrm{mmHg}$, whereas only $57 \%$ of those under multidrug-therapy group reached that goal. The relationship of BP control with the type of therapy and the number of drugs used is shown in Figure 3. As expected, a greater use of a combination 
TABle 3: Proportion of cardiovascular risk factors in 1,194 hypertensive patients (CHP). Comparison with hypertensive and normotensive individuals from the 2010 National Health Survey (NHS).

\begin{tabular}{|c|c|c|c|}
\hline & $\begin{array}{c}\text { Hypertensive CHP } \\
n=1,194\end{array}$ & $\begin{array}{l}\text { Hypertensive NHS } 2010 \\
n=1,101\end{array}$ & $\begin{array}{c}\text { Normotensive NHS } 2010 \\
n=3,775\end{array}$ \\
\hline \multirow[t]{2}{*}{ Average age (years) } & $63.3 \pm 13.6$ & $62.5 \pm 13.9$ & $40.1 \pm 16.4$ \\
\hline & & Percentage \% (CI 95\%) & \\
\hline Diabetes mellitus & $26.4(24.0-29.0)$ & $17.5(15.3-19.7)^{*}$ & $3.2(2.6-3.7)^{\dagger}$ \\
\hline $\begin{array}{l}\text { Glycemia } \\
\qquad(\geq 100 \mathrm{mg} / \mathrm{dL})\end{array}$ & $44.3(41.5-47.1)$ & $55.7(50.2-61.2)^{*}$ & $29.6(28.1-31.1)^{\dagger}$ \\
\hline Smoking & $18.0(15.8-20.2)$ & $19.1(16.8-21.4)$ & $40.2(38.6-41.8)^{\dagger}$ \\
\hline $\begin{array}{l}\text { Overweight } \\
\qquad\left(\text { BMI } 25.0-29.9 \mathrm{Kg} / \mathrm{m}^{2}\right)\end{array}$ & $39.4(36.6-42.1)$ & $35.8(32.9-38.6)$ & $36.4(34.9-37.9)$ \\
\hline $\begin{array}{l}\text { Obesity } \\
\qquad\left(\mathrm{BMI} \geq 30 \mathrm{Kg} / \mathrm{m}^{2}\right)\end{array}$ & $42.8(40.0-45.6)$ & $44.4(41.5-47.3)^{*}$ & $23.5(22.1-24.9)^{\dagger}$ \\
\hline $\begin{array}{l}\text { Total cholesterol } \\
\qquad(\geq 200 \mathrm{mg} / \mathrm{dL})\end{array}$ & $35.4(32.5-38.2)$ & $37.2(34.3-40.1)$ & $53.1(51.5-54.7)^{\dagger}$ \\
\hline $\begin{array}{l}\text { Low education } \\
<8 \text { years }\end{array}$ & $58.8(55.6-62.8)$ & $27.9(25.3-30.5)^{*}$ & $47.5(45.9-49.0)^{\dagger}$ \\
\hline
\end{tabular}

${ }^{*} P<0.01$ for comparison with CHP sample, ${ }^{\dagger} P<0.01$ for comparison with CHP sample.

TABLE 4: Cardiovascular risk factors: comparison between hypertensive diabetic and nondiabetic patients.

\begin{tabular}{|c|c|c|c|}
\hline Risk factors & $\begin{array}{l}\text { Hypertensive nondiabetic } \\
\qquad n=882\end{array}$ & $\begin{array}{l}\text { Hypertensive diabetic } \\
\qquad n=312\end{array}$ & $\begin{array}{c}\text { OR (IC 95\%) } \\
n=1,194\end{array}$ \\
\hline \multirow[t]{2}{*}{ Average age (years) } & $62.9 \pm 14.0$ & $64.0 \pm 12.2$ & - \\
\hline & & Percentage \% (CI 95\%) & \\
\hline Blood pressure $\geq 140 / 90 \mathrm{mmHg}$ & $38.0(34.7-41.2)$ & $46.8(41.3-52.3)^{*}$ & $1.41(1.08-1.84)$ \\
\hline Blood pressure $\geq 130 / 80 \mathrm{mmHg}$ & $75.1(72.2-77.9)$ & $78.5(73.9-83.0)^{*}$ & $1.19(0.87-1.62)$ \\
\hline Total cholesterol $200-239 \mathrm{mg} / \mathrm{dL}$ & $36.5(33.1-39.8)$ & $32.6(27.1-38.0)^{*}$ & $0.84(0.63-1.12)$ \\
\hline Total cholesterol $\geq 240 \mathrm{mg} / \mathrm{dL}$ & $23.9(21.0-26.9)$ & $20.7(15.9-25.4)^{*}$ & $0.83(0.60-1.17)$ \\
\hline HDL cholesterol $<40 \mathrm{mg} / \mathrm{dL}$ & $19.3(16.5-22.0)$ & $32.4(26.6-37.5)^{*}$ & $2.03(1.45-2.85)$ \\
\hline Overweight (BMI $25.0-29.0 \mathrm{Kg} / \mathrm{m}^{2}$ ) & $40.7(37.5-43.9)$ & $35.3(30.0-40.6)^{*}$ & $0.78(0.59-1.01)$ \\
\hline Obesity $\left(\mathrm{BMI} \geq 30 \mathrm{Kg} / \mathrm{m}^{2}\right)$ & $39.5(36.3-42.7)$ & $51.9(46.3-57.4)^{*}$ & $1.79(1.37-2.38)$ \\
\hline Low education $(<8 \text { years })^{\dagger}$ & $39.3(35.1-43.5)$ & $44.5(37.8-51.2)^{*}$ & $1.34(1.32-1.38)$ \\
\hline Smoking ${ }^{\dagger \dagger}$ & $18.3(15.7-20.8)$ & $16.1(12.0-20.2)^{*}$ & $1.51(1.47-1.55)$ \\
\hline
\end{tabular}

OR refers to odds ratio adjusted by age and gender; the reference group is hypertensive nondiabetic; ${ }^{\dagger}$ the category for nonresponse (38\%) is included in multivariate analyses; ${ }^{\dagger}$ OR estimated for the category of daily smoker, including the category for nonresponse in multivariate analyses; ${ }^{*} P<0.01$ for comparison with nondiabetic hypertensive patients.

(a) Hypertensive nondiabetic

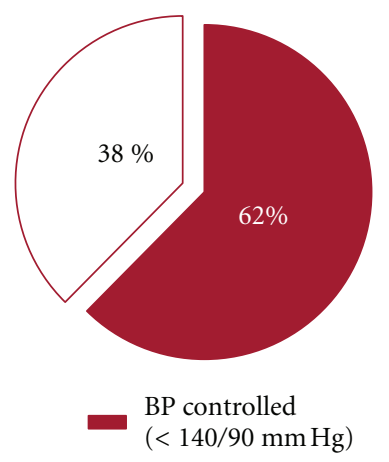

(b) Hypertensive diabetic

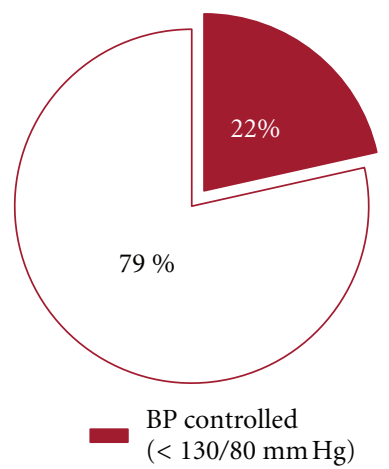

FIGURE 1: Proportion of satisfactory blood pressure (BP) control in the hypertensive population followed through the Cardiovascular Health Program according to diabetic status. 
TABle 5: Association of different factors with the control of blood pressure (BP) in a cohort of hypertensive patients, Cardiovascular Health Program (CHP), Chile.

\begin{tabular}{|c|c|c|c|}
\hline Risk factors & $\begin{array}{c}\mathrm{BP}<140 / 90 \mathrm{mmHg} \\
n=713\end{array}$ & $\begin{array}{c}\mathrm{BP} \geq 140 / 90 \mathrm{mmHg} \\
n=481\end{array}$ & $\begin{array}{c}\text { OR (IC95\%) } \\
n=1,194\end{array}$ \\
\hline \multirow[t]{2}{*}{ Average age (years) } & $61.9 \pm 13.5$ & $65.3 \pm 13.4$ & - \\
\hline & & Percentage \% (CI 95\%) & \\
\hline Diabetes mellitus & $23.3(20.2-26.4)$ & $30.4(26.3-34.5)$ & $1.39(1.37-1.41)$ \\
\hline Total cholesterol 200-239 mg/dL & $30.4(27.0-33.8)$ & $34.1(29.9-38.3)$ & $1.18(1.16-1.20)$ \\
\hline Total cholesterol $>240 \mathrm{mg} / \mathrm{dL}$ & $20.9(17.9-23.9)$ & $20.6(17.0-24.2)$ & $1.02(1.01-1.04)$ \\
\hline HDL cholesterol < 40 mg/dL & $21.6(18.6-24.6)$ & $25.2(21.3-29.1)$ & $1.17(1.15-1.20)$ \\
\hline Overweight (BMI $25.0-29.0 \mathrm{Kg} / \mathrm{m}^{2}$ ) & $38.3(34.7-41.9)$ & $40.7(36.3-45.1)$ & $1.03(1.01-1.04)$ \\
\hline Obesity $\left(\mathrm{BMI}>30 \mathrm{Kg} / \mathrm{m}^{2}\right)$ & $42.4(38.8-46.0)$ & $43.2(38.8-47.6)$ & $1.17(1.15-1.18)$ \\
\hline Low education $(<8 \text { years })^{\dagger}$ & $22.6(19.5-25.7)$ & $28.5(24.5-32.5)$ & $1.29(1.27-1.38)$ \\
\hline Smoking & $19.6(16.7-22.5)$ & $14.8(11.6-18.0)$ & $0.97(0.95-0.99)$ \\
\hline Presence cardiovascular deiseases ${ }^{\Psi}$ & $8.9(6.8-11.0)$ & $8.3(5.8-10.8)$ & $0.77(0.75-0.79)$ \\
\hline
\end{tabular}

$\mathrm{OR}$ refers to odds ratio adjusted by age and gender; the group of reference is $\mathrm{BP}<140 / 90$; ${ }^{\dagger}$ the category for nonresponse (38\%) is included in multivariate analyses; ${ }^{*} P<0.01$ for comparison with BP controlled, ${ }^{\Psi}$ presence of stroke, heart failure, and ischemic heart disease.

of antihypertensive drugs (more often ACEI, angiotensin receptor blockers (ARBs), $\beta$-blockers and diuretics) occurred in hypertensive patients with BP more difficult to control. Some combinations appeared to be more effective than others (ACEI + diuretic and Calcium channel blocker + diuretic versus $\beta$-blocker + diuretic and ARB + diuretic) (Figure 3 ). There were no differences in the drug monotherapy utilized in nondiabetic and diabetic hypertensive patients. ACEI plus diuretics were more commonly used in nondiabetics, and ARBs plus diuretics more often provided to diabetic patients (Table 6).

\section{Discussion}

This study, which included a representative sample of the hypertensive population followed through the Chilean Cardiovascular Health Program (CHP) in the metropolitan region of Santiago (316,654 patients), documented a BP control of $<140 / 90 \mathrm{mmHg}$ in $59.7 \%$ of the patients and $91.5 \%$ under antihypertensive drug therapy, comparable to the best results obtained elsewhere [12]. In recent data released by the Center of Disease Control in USA based in the National Health and Nutrition Examination Survey (NHANES) only $69 \%$ of hypertensive patients were under antihypertensive drug therapy and $46 \%$ had their BP $<140 / 90 \mathrm{mmHg}$ [5]. Furthermore, a significant improvement was documented in reference to previous Chilean National Health Surveys that showed only $45.3 \%$ patients reaching that goal [11]. These findings suggest that a primary care system with a program aiming to detect hypertensive patients and provide them with unrestricted access to medical monitoring and a comprehensive treatment program including lifestyle changes counseling can be an effective preventive strategy.

Nowadays, there is agreement that the simple access to medical followup through provision of medical insurance has not shown satisfactory BP control in hypertensive patients $[2,3,5,7]$. Interestingly $8.5 \%$ of patients in our primary care-based cohort were managed exclusively with nonpharmacological measures, and $75 \%$ reached a target $\mathrm{BP}$ $<140 / 90 \mathrm{mmHg}$ underscoring the importance of access to ancillary services as dietary and lifestyle changes counseling (e.g., increasing physical activity) along with the medical followup. In contrast, drug combinations were used in more than $50 \%$ of the subjects, achieving the desired goal of $\mathrm{BP}<$ $140 / 90 \mathrm{mmHg}$ only in $57 \%$ and as expected, less frequently in patients with higher and more difficult BP to control. These results are probably reflecting differences in the severity of hypertension, therapeutic adherence, or other unknown factors in the population studied.

In regard to the factors identified to influence the control of BP, after adjusting for age and gender in this Chilean hypertensive cohort, diabetes and low education level were associated to worse BP control-and, to a lesser extent, obesity and blood lipids. The association between poor control of BP and other CVRF is probably a reflection of the difficulties for simultaneously controlling multiple risk factors, especially in diabetic hypertensive patients. On the other hand, in cross-sectional and prospective cohort studies in different countries-including Chilean adults—an inverse association between education level and CVRF, cardiovascular events and all-cause mortality has been consistently established [13-21]. This study provides additional evidence suggesting that low educational level seems to be a predictor of poor control of BP in Chilean hypertensive patients. Plausible explanations are related to the acquired skills and knowledge for self-care, healthy lifestyles, and better adherence to antihypertensive therapies with increasing education levels [21]. The presence of cardiovascular complications also showed association with controlled BP, perhaps due to a difference in the lifestyle modification counseling and a better adherence to antihypertensive drug therapy after incidental complications.

Several findings in this study represent a significant challenge for the CHP. First, the much larger proportion of women than men (ratio $2.1: 1$ ) who entered the CHP is 


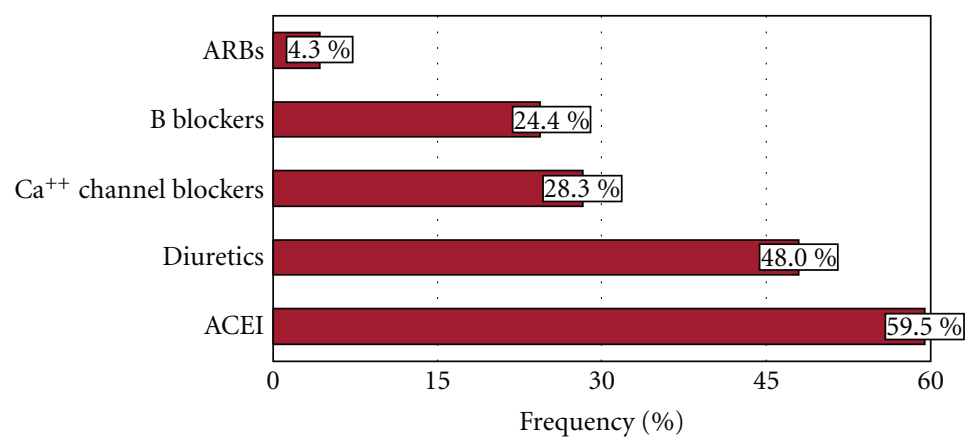

Figure 2: Antihypertensive drugs utilized in the Cardiovascular Health Program (CHP).

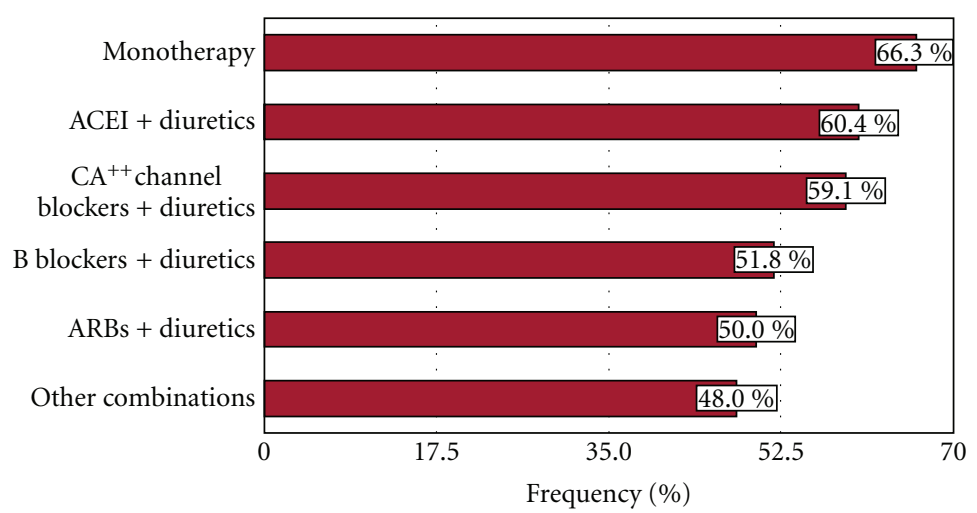

FIgure 3: Antihypertensive drug therapy modalities used to achieve BP control $(<140 / 90 \mathrm{mmHg})$ in the Cardiovascular Health Program $(\mathrm{CHP})$.

not consistent with the Chilean prevalence of hypertension, which is similar in both genders according to previous National Health Surveys [11]. This fact indicates that the program is not providing adequate coverage to the male population. Probably labor-related hurdles in men limit their availability for routine medical followups in contrast to women, most of them homemakers with more flexible time at their disposal. Second, the large proportion of hypertensive diabetic patients with unsatisfactory BP control, $22 \%$ reaching the recommended $\mathrm{BP}<130 / 80 \mathrm{mmHg}$, underscores the need to improve the BP management in this group. In addition, they had a higher proportion of obesity and lower HDL than nondiabetic hypertensive patients making them particularly vulnerable to cardiovascular events. Finally, this study shows that the presence of diabetes in this hypertensive population is significantly higher $(26.4 \%)$ than the prevalence $(5.1 \%)$ in the general Chilean population [11]. According to these results, over 100,000 patients treated in the CHP present a comorbidity of hypertension and diabetes in the metropolitan area. It is conceivable that a better management of these patients at the primary care level may have a significant impact in reducing the morbidity, mortality, and costs related to cardiovascular complications in this highly vulnerable group of patients [22]. Others have already reported this problem. A CVRF trends study in nondiabetic and Type 2 diabetic patients followed for 35 years (1970-2005, Framingham Heart Study) showed consistently higher BP in diabetics [23]. In Spain, a study found that only $9.8 \%$ of the hypertensive diabetics had a BP at the recommended target of $<130 / 80 \mathrm{mmHg}$. Some have questioned whether the proposed level of control for diabetic hypertensive patients $(\mathrm{BP}<130 / 80 \mathrm{mmHg}$ ) is necessary or achievable from the perspective of public health $[24,25]$. Our experience in the CHP confirms the difficulties in reaching that goal.

Like the pioneering studies from the Framingham cohort [26], a Chilean prospective cohort study (San Francisco Project) has suggested that an adequate BP control may significantly reduce nonfatal cardiovascular events (myocardial infarction, unstable angina, and cerebrovascular accidents) in hypertensive population, estimating $80.3 \%$ reduction after 5 years (population attributable risk) [16]. Considering this estimate, the adequate BP control in $59.7 \%$ of patients could achieve $47.9 \%$ reduction of cardiovascular complications after 5 years of followup in the CHP. When compared to the National Health Survey $(45.3 \%$ achieving BP < $140 / 90 \mathrm{mmHg}$ ), the CHP could predict an additional $11.5 \%$ reduction in cardiovascular events in hypertensive population.

There are several limitations in our study. One of them is that we did not determine drug adherence, which will be the subject of a future study. Poor adherence could have been a factor to explain the worst BP control in diabetics. Recently it has been suggested that in diabetics the buffering 
TABLE 6: Comparison of antihypertensive treatment modalities in hypertensive diabetic and nondiabetic patients.

\begin{tabular}{|c|c|c|c|}
\hline Treatment modalities & $\begin{array}{l}\text { Hypertensive nondiabetic patients } \\
\qquad n=882(\%)\end{array}$ & $\begin{array}{l}\text { Hypertensive diabetic patients } \\
\qquad n=312(\%)\end{array}$ & $P$-value \\
\hline Nonpharmacological & 9.0 & 7.1 & 0.298 \\
\hline Pharmacological & 91.0 & 92.9 & 0.298 \\
\hline Monotherapy & 34.2 & 34.6 & 0.904 \\
\hline ACEI + diuretic & 20.7 & 15.1 & 0.028 \\
\hline Calcium channel blockers + diuretic & 6.8 & 6.1 & 0.663 \\
\hline$\beta$-blockers + diuretic & 2.5 & 2.4 & 0.804 \\
\hline $\mathrm{ARBs}+$ diuretic & 0.1 & 1.6 & 0.006 \\
\hline Other drugs combination & 24.5 & 29.8 & 0.065 \\
\hline
\end{tabular}

effect of hypertension on pain sensitivity previously reported by several studies may be magnified, leading to hyperalgesia and therefore to a reluctance of diabetic hypertensive patients to follow the antihypertensive treatment [27-30]. However, one of the inclusion criteria for this study was that patients regularly attended their medical appointments, which could be an indirect suggestion that many of them adhered to the recommended therapy. This requirement may also partially explain the differences found with the results of the previous National Health Survey based on general population [11]. In addition the number of men included in the study compared to women was significantly smaller, and this may have influenced some of the results. Nevertheless, because the CHP is now a part of the primary care program in Chile, the number of hypertensive patients to be followed in the future is expected to increase along with the proportion of men included.

It was of note that the frequency of smoking was lower in this hypertensive population than the prevalence observed in the general population of the Chilean National Health Survey [11], difference that may be related to the lifestyle modification counseling as a part of the CHP. Other positive lifestyle modifications in this population can include reduced salt consumption and increased physical activity. These findings along with the improvements in achieving a satisfactory BP control underscore the significance of the CHP in the Chilean hypertensive population.

\section{Conclusions}

A Cardiovascular Health Program that provides unrestricted access to comprehensive treatment and followup of hypertensive patients seems to be an effective strategy to address a major cardiovascular preventive goal in a middle-income developing country as Chile.

According to the results of this study and based on projections from previous studies it is expected that by improving $\mathrm{BP}<140 / 90 \mathrm{mmHg}$ to $59.7 \%$ as a consequence of the $\mathrm{CPH}, 47.9 \%$ reduction of future nonfatal cardiovascular events might occur in the hypertensive population of this program. Remaining challenges are the need to improve the underrepresentation of men and the management of hypertensive diabetic patients.

\section{Acknowledgments}

This study was partially supported by the research grants FA122006 and FA02052011, Fundación Araucaria, San Diego, CA. The authors would like to thank the invaluable assistance of the health care professionals and administrative personnel in carrying out this study at the following 52 primary care centers: Posta Alhué (Alhué), Héctor García (Buín), Los bajos de San Agustín (Calera de Tango), Nurse Sofía Pincheira (Cerrillos), Cerro Navia (Cerro Navia), Postas rurales Esmeralda (Colina); Eneas Gonel (Conchalí), Posta de Curacaví (Curacaví), Cisterna Sur (El Bosque), El Monte (El Monte), San José de Chuchunco (Estación Central), La Pincoya (Huechuraba), Dr. Agustín Cruz Melo (Independencia), Postas rurales Isla de Maipo (Isla de Maipo); Eduardo Frei Montalva (La Cisterna), Bellavista (La Florida), Malaquías Concha (La Granja), San Rafael (La Pintana), La Reina (La Reina), Batuco (Lampa), Dr. Anibal Ariztía (Las Condes), Lo Barnechea (Lo Barnechea), Julio Acuña Pinzón (Lo Espejo), Avendaño (Lo Prado), Félix de Amesti (Macul), Maipú (Maipú), María Pinto (María Pinto), Dr. Boris Soler (Melipilla), Salvador Bustos (Ñuñoa), Juan Pablo II (Padre Hurtado), Hospital de Paine (Paine), Amador Neghme (Pedro Aguirre Cerda), Fernando Monckeberg (Peñaflor), La Faena (Peñalolen), Pirque (Pirque), Hernán Alessandri (Providencia), Dr. Gustavo Molina (Pudahuel), Alejandro de Rio (Puente Alto), Manuel Bustos (Quilicura), Lo Franco (Quinta Normal), Quinta Bella (Recoleta), Hernán Urzúa (Renca), Carol Urzúa (San Bernardo), San Joaquín (San Joaquín), Posta Las Vertientes (San José de Maipo), Barros Luco (San Miguel), San Pedro (San Pedro), San Ramón (San Ramón), Consultorio number 5 (Santiago), Dr. Alberto Alessandri (Talagante), Til til (Til til, Consultorio Adosado), Vitacura (Vitacura).

\section{References}

[1] D. R. Berlowitz, A. S. Ash, E. C. Hickey et al., "Inadequate management of blood pressure in a hypertensive population," The New England Journal of Medicine, vol. 339, no. 27, pp. 1957-1963, 1998.

[2] I. Hajjar and T. A. Kotchen, "Trends in prevalence, awareness, treatment, and control of hypertension in the United States, 1988-2000," Journal of the American Medical Association, vol. 290, no. 2, pp. 199-206, 2003. 
[3] R. Sequeira, K. Jassim Al Khaja, and A. Damanhori, "Evaluating the treatment of hypertension in diabetes mellitus: a need for better control?" Journal of Evaluation in Clinical Practice, vol. 10, no. 1, pp. 107-116, 2004.

[4] E. Fasce, I. Campos, P. Ibáñez et al., "Trends in prevalence, awareness, treatment and control of hypertension in urban communities in Chile," Journal of Hypertension, vol. 25, no. 9, pp. 1807-1811, 2007.

[5] Centers for Disease Control and Prevention, "Vital signs: prevalence, treatment, and control of hypertension-United States, 1999-2002 and 2005-2008," Morbidity and Mortality Weekly Report, vol. 60, pp. 1-6, 2011.

[6] J. M. Kotchen, B. Shakoor-Abdullah, W. E. Walker, T. H. Chelius, R. G. Hoffmann, and T. A. Kotchen, "Hypertension control and access to medical care in the inner city," American Journal of Public Health, vol. 88, no. 11, pp. 1696-1699, 1998.

[7] D. M. Lloyd-Jones, J. C. Evans, M. G. Larson, and D. Levy, "Treatment and control of hypertension in the community: a prospective analysis," Hypertension, vol. 40, no. 5, pp. 640-646, 2002.

[8] T. Romero and C. X. Romero, "Stagnant cardiovascular prevention: alarming trends and persistent socioeconomic obstacles," Revista Espanola de Cardiologia, vol. 63, no. 11, pp. 1340 $1348,2010$.

[9] Ministry of Health (Ministerio de Salud), Chile, Adult Health Program. Hypertension and Diabetes Programs, 2002 http:// www.redsalud.gov.cl/archivos/saludcardiovascular/Reorientacion_de_los_Programas_de_Hipertension_y_Diabetes.pdf.

[10] National Institute of Statistics (Instituto Nacional de Estadísticas-INE), "General Vital and Mortality Statistics," 2008, http ://www.ine.cl/canales/menu/publicaciones/calendario_ de_publicaciones/pdf/21_12_10/vit_08211210.pdf.

[11] Ministry of Health (Ministerio de Salud, MINSAL), National Health Survey, Chile, Vol. 1. Santiago, 2009-2010, http:// www.minsal.gob.cl/portal/url/item/bcb03d7bc28b64dfe04001 0165012d23.pdf.

[12] S. Y. Angell, R. K. Garg, R. C. Gwynn, L. Bash, L. E. Thorpe, and T. R. Frieden, "Prevalence, awareness, treatment, and predictors of control of hypertension in New York City," Circulation, vol. 1, no. 1, pp. 46-53, 2008.

[13] M. A. Albert, R. J. Glynn, J. Buring, and P. M. Ridker, "Impact of traditional and novel risk factors on the relationship between socioeconomic status and incident cardiovascular events," Circulation, vol. 114, no. 24, pp. 2619-2626, 2006.

[14] E. Koch, T. Romero, L. Manríquez et al., "Socioeconomic and educational inequities as independent predictors for mortality in a developing country: a cohort study in San Francisco, Chile," Revista Medica de Chile, vol. 135, no. 11, pp. 13701379, 2007.

[15] J. W. Lynch, G. A. Kaplan, R. D. Cohen, J. Tuomilehto, and J. T. Salonen, "Do cardiovascular risk factors explain the relation between socioeconomic status, risk of all-cause mortality, cardiovascular mortality, and acute myocardial infarction?" American Journal of Epidemiology, vol. 144, no. 10, pp. 934942, 1996.

[16] E. Koch, A. Otarola, L. Manríquez, A. Kirschbaum, M. Paredes, and C. Silva, "Predictors of non-fatal cardiovascular events in a Chilean urban population. The San Francisco project experience," Revista Medica de Chile, vol. 133, pp. 1002-1012, 2005.

[17] A. I. Qureshi, M. F. Suri, M. Saad, and L. N. Hopkins, "Educational attainment and risk of stroke and myocardial infarction," Medical Science Monitor, vol. 9, no. 11, pp. CR466CR473, 2003.
[18] K. Steenland, J. Henley, and M. Thun, "All-cause and causespecific death rates by educational status for two million people in two American cancer society cohorts, 1959-1996," American Journal of Epidemiology, vol. 156, no. 1, pp. 11-21, 2002.

[19] E. Koch, T. Romero, C. X. Romero et al., "Early life and adult socioeconomic influences on mortality risk: preliminary report of a "Pauper Rich" paradox in a chilean adult cohort," Annals of Epidemiology, vol. 20, no. 6, pp. 487-492, 2010.

[20] Y. H. Khang and H. R. Kim, "Explaining socioeconomic inequality in mortality among South Koreans: an examination of multiple pathways in a nationally representative longitudinal study," International Journal of Epidemiology, vol. 34, no. 3, pp. 630-637, 2005.

[21] E. Koch, T. Romero, C. X. Romero et al., "Impact of education, income and chronic disease risk factors on mortality of adults: does "a pauper-rich paradox" exist in Latin American societies?" Public Health, vol. 124, no. 1, pp. 39-48, 2010.

[22] P. M. Clarke, A. M. Gray, A. Briggs, R. J. Stevens, D. R. Matthews, and R. R. Holman, "Cost-utility analyses of intensive blood glucose and tight blood pressure control in type 2 diabetes (UKPDS 72)," Diabetologia, vol. 48, no. 5, pp. $868-$ 877, 2005.

[23] S. R. Preis, M. J. Pencina, S. J. Hwang et al., "Trends in cardiovascular disease risk factors in individuals with and without diabetes mellitus in the framingham heart study," Circulation, vol. 120, no. 3, pp. 212-220, 2009.

[24] C. Escobara, V. Barriosa, A. Calderónb, S. García, G. C. Rodríguez-Rocad y, and A. Matalíe, "Diabetes in the hypertensive population under primary care in Spain. Blood pressure and lipids control," Revista Clinica Espanola, vol. 207, no. 5, pp. 221-227, 2007.

[25] J. A. Alemán, M. Á. Díaz, M. L. Hernández et al., "Evaluation and control of hipertensive diabetics seen in primary care centres in Spain. BRAND II study," Atención Primaria, vol. 43, no. 6, pp. 297-304, 2011.

[26] W. Kannel and P. Wolf, "Framingham study insights on the hazards of elevated blood pressure," Journal of the American Medical Association, vol. 300, no. 21, pp. 2545-2547, 2008.

[27] K. Hagen, J. Zwart, J. Holmen, S. Svebak, G. Bovim, and L. Stovner, "Does hypertension protect against chronic musculoskeletal complaints? The Nord-Trøndelag health study," Archives of Internal Medicine, vol. 165, no. 8, pp. 916-922, 2005.

[28] E. Koch, T. Romero, M. Bravo et al., "Coexisting diabetes and hypertension reduced the frequency of musculoskeletal pain visits: suggestions of a synergic hypoalgesic effect in a Cohort of 1,194 hypertensive patients," Circulation, vol. 124, Article ID A12027, 2011.

[29] S. Bruehl and O. Y. Chung, "Interactions between the cardiovascular and pain regulatory systems: an updated review of mechanisms and possible alterations in chronic pain," Neuroscience and Biobehavioral Reviews, vol. 28, no. 4, pp. 395-414, 2004.

[30] T. S. Campbell, B. Ditto, J. R. Séguin, S. Sinray, and R. E. Tremblay, "Adolescent pain sensitivity is associated with cardiac autonomic function and blood pressure over 8 years," Hypertension, vol. 41, no. 6, pp. 1228-1233, 2003. 


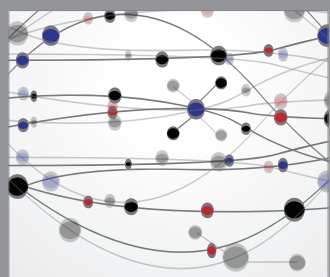

The Scientific World Journal
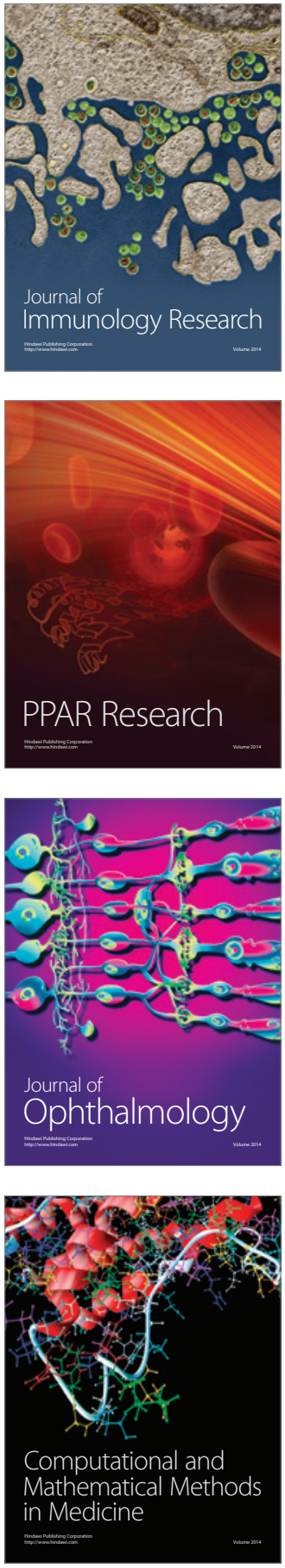

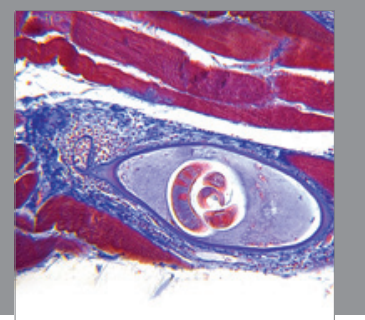

Gastroenterology

Research and Practice
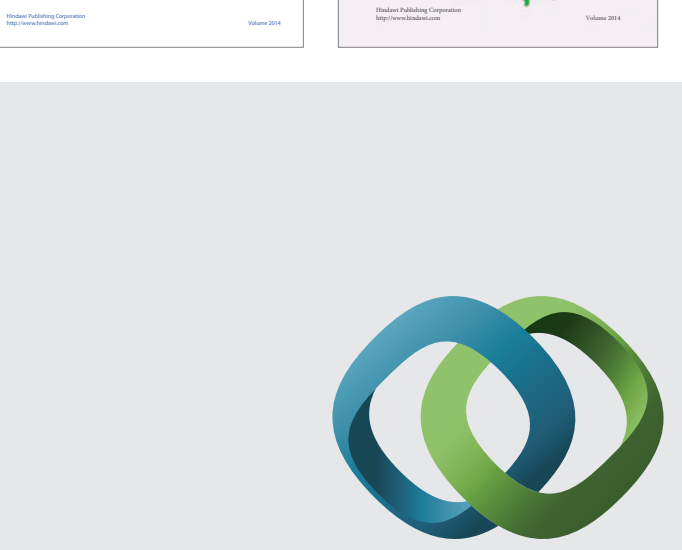

\section{Hindawi}

Submit your manuscripts at

http://www.hindawi.com
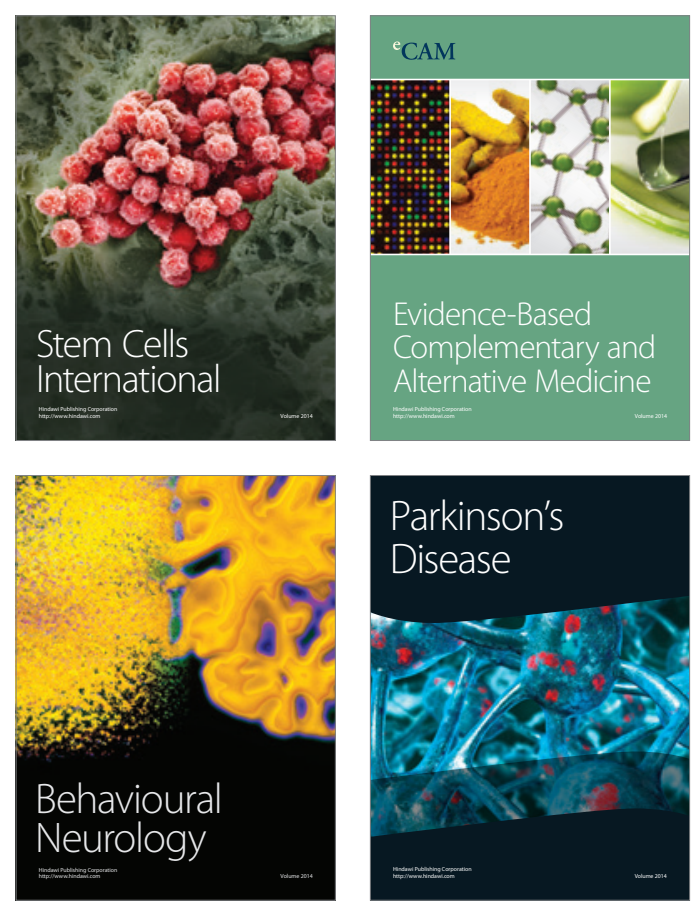

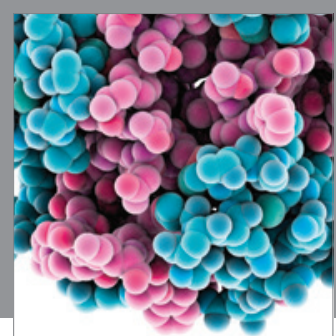

Journal of
Diabetes Research

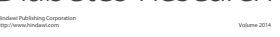

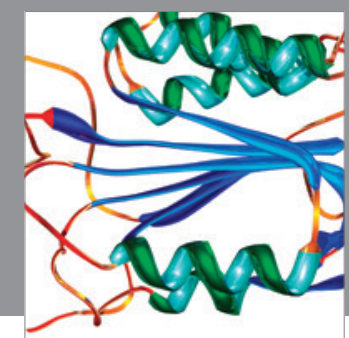

Disease Markers
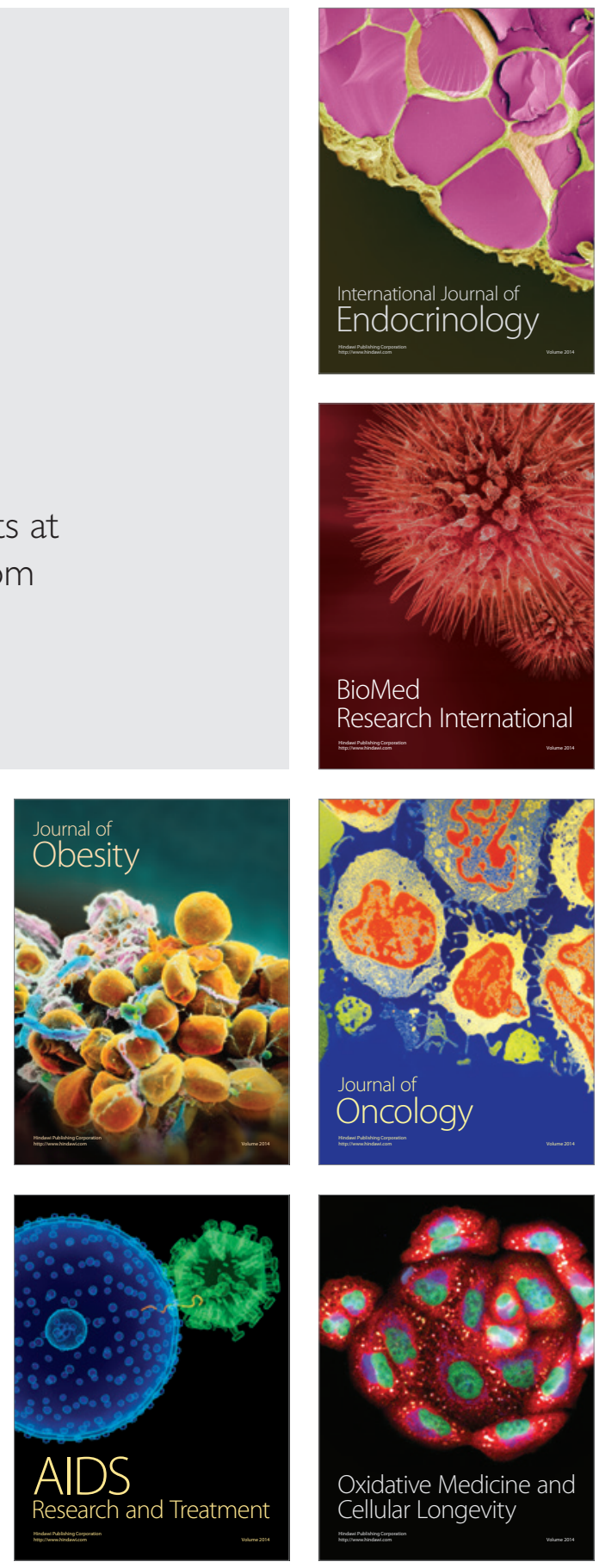